\title{
Facile synthesis of copper doped ZnO nanorods for the efficient photo degradation of methylene blue and methyl orange
}

Aqeel Ahmed Shah, Muhammad Ali Bhatti, Aneela Tahira, Ali Dad Chandio, Iftikhar A. Channa, Ali Ghulam Sahito, Seyed Ebrahim Chalangar, Magnus Willander, Omer Nur and Zafar Hussain Ibupoto

The self-archived postprint version of this journal article is available at Linköping University Institutional Repository (DiVA):

http://urn.kb.se/resolve?urn=urn:nbn:se:liu:diva-165917

N.B.: When citing this work, cite the original publication.

Shah, A. A., Bhatti, M. A., Tahira, A., Chandio, A. D., Channa, I. A., Sahito, A. G., Chalangar, S. E., Willander, M., Nur, O., Ibupoto, Z. H., (2020), Facile synthesis of copper doped ZnO nanorods for the efficient photo degradation of methylene blue and methyl orange, Ceramics International, 46(8), 9997-10005. https://doi.org/10.1016/j.ceramint.2019.10.024

Original publication available at:

https://doi.org/10.1016/j.ceramint.2019.10.024

Copyright: Elsevier

http://www.elsevier.com/

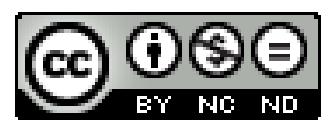




\title{
Facile synthesis of copper doped $\mathrm{ZnO}$ nanorods for the efficient photo degradation of methylene blue and methyl orange
}

Aqeel Ahmed Shah ${ }^{\mathrm{a}}$, Muhammad Ali Bhatti ${ }^{\mathrm{b}}$, Aneela Tahira ${ }^{\mathrm{e}}$, Ali Dad Chandio ${ }^{\mathrm{a}}$, Iftikhar A. Channa $^{\mathrm{a}}$, Ali Ghulam Sahito ${ }^{\mathrm{d}}$, Syed Ebrahim ${ }^{\mathrm{e}}$, Magnus Willander ${ }^{\mathrm{e}}$, Omer Nur ${ }^{\mathrm{e}}$, Zafar Hussain Ibupoto* c

${ }^{a}$ NED University of Engineering and Technology Karachi, Pakistan

${ }^{b}$ Department of Environmental Sciences University of Sindh Jamshoro, 76080, Sindh Pakistan

${ }^{c}$ Dr. M.A Kazi Institute of Chemistry University of Sindh Jamshoro, 76080, Sindh Pakistan

${ }^{\mathrm{d}}$ Centre for Pure and Applied Geology, University of Sindh Jamshoro, 76080, Sindh, Pakistan

e Department of Science and Technology, Campus Norrkoping, Linkoping University, SE-60174 Norrkoping, Sweden

*Corresponding author: Zafar Hussain Ibupoto

Email address: zaffar.ibhupoto@usindh.edu.pk

\begin{abstract}
In this study, zinc oxide $(\mathrm{ZnO})$ nanorods are doped with copper by low temperature aqueous chemical growth method using different concentrations of copper $5 \mathrm{mg}, 10 \mathrm{mg}, 15 \mathrm{mg}$ and $20 \mathrm{mg}$ and labeled as sample 1, 2, 3 and 4 respectively. The morphology and phase purity of nanostructures was investigated by scanning electron microscopy, and powder X-ray diffraction techniques. The optical characterization was carried out through UV-Vis spectrophotometer. The band gap of coper doped $\mathrm{ZnO}$ has brought reduction at 250-600 $\mathrm{nm}$ and it indicates the fewer time for the recombination of electron and hole pairs, thus enhanced photo degradation efficiency is found. $\mathrm{ZnO}$ exhibits nanorods like shape even after the doping of copper. The photo degradation efficiency for the two chronic dyes such as methyl orange MO and methylene blue MB was found to be $57.5 \%$ and $60 \%$ respectively for a time of 180 mints. This study suggests that the copper impurity in $\mathrm{ZnO}$ can tailor its photocatalytic activity at considerable rate. The proposed photo
\end{abstract}


catalysts are promising and can be used for the waste water treatment and other environmental applications.

Keywords: Methylene blue, methyl orange, copper doping, band gap, ZnO nanostructures, photocatalysis

\section{Introduction:}

Development of any country is depending on the progress made in the industrial products. At the same time, industry produces several pollutants such as effluent, gaseous and solid wastes which bring the severe effect on the life. These pollutants are causing the air pollution and their release into natural water gives water pollution. Among the pollutants, the industrial dyes are creating a significant damage in our environment [1]. Therefore, the degradation of these dyes is a big challenge using a simple strategy and is known as a hot spot for the investigation for improving the quality of environment and ultimately to best of our life [2-4]. The potential and promising strategy is the photo catalysis for the degradation of dyes and it does not produce any secondary pollutants [5]. Also, photo catalysis is economic, nontoxic, consumes less energy, and can be reused [6]. Several, photocatalysts are developed and among them oxide semiconductors are found to be efficient for the photodegradation such as $\mathrm{TiO}_{2}[7,8]$ that is intensively used due to its strong absorption in the UV region. However, $\mathrm{TiO}_{2}$ is associated with certain limitations such as high recombination rate, low quantum yield [9] in water media and wide band gap. The wide bandgap allows $\mathrm{TiO}_{2}$ to absorb only UV light which is approximately $4 \%$ of the white light (Sun light), thus low photo conversion efficiency is so far received in photocatalysis. Because of these reasons both the researchers and industrialists are searching for the alternative potential photocatalysts and in this regard, $\mathrm{ZnO}$ has received lot of attention [10] due to its promising properties in the photo catalysis $[11,12,13,14,15]$, photo degradation [16], as well as in in other several applications such as gas sensors [17], solar cells [18], transistors [19], light emitting devices [20], and cancer treatment [21]. ZnO has several advantageous features such as inexpensive, earth abundant, can be produced with high yield, environment friendly, chemical and thermally stable [13]. ZnO exhibits better photo catalytic activity than $\mathrm{TiO}_{2}$ with higher quantum efficiency [22] [23, 24] as it absorbs larger fraction of solar spectrum than $\mathrm{TiO}_{2}$. Despite these useful features $\mathrm{ZnO}$ also experiences the limitations such as high recombination rate and consequently poor photocatalytic activity is found. The poor efficiency of $\mathrm{ZnO}$ is improved through doping that has shown 
considerable impact on the optical band of $\mathrm{ZnO}[25,26]$. Several dopants including Fe, Ag, Ni, $\mathrm{Co}, \mathrm{Mn}$ and copper are used for $\mathrm{ZnO}$ [27-33]. Among them copper shows unique features such as, similar size to that of zinc, improves the separation of charge carriers, possess greater surface area, brings a reduction in the optical band gap and can produces lattice defects in semiconducting photo catalyst [34] and further it facilitates the photo catalytic properties [14], The one dimensional nanostructures such as nanowires/nanorods are the most suitable for the photo catalysis due to their large surface to volume ratio and they play a dynamic role in the photo catalytic activity, thus doping the $\mathrm{ZnO}$ by maintaining the morphology is a key challenge with outperform photo conversion efficiency [35].

It has been reported in literature [36-37] that photocatalytic efficiency is dependent upon band gap and increases with decrease in band gap. Abdus Saboor and co-workers [38] succeed in remarkable decrease in band gap by $19.27 \%$ with Ag doping and by $18.96 \%$ with $\mathrm{Nd}$ doped $\mathrm{ZnO}$. A.Modvi and coworkers [39] reduced the band gap of $\mathrm{ZnO}$ while inducing copper in combination with transition metals. They achieved band gap reduction by $6.35 \%$ with copper doping and upto $11.43 \%$ with doping copper in combination with Ag. The effect of copper dopant on the photo catalytic degradation is rarely investigated and further its governing role on the photo degradation efficiency is remained unexplored but this study has shown them systematically.

In this study, we have successfully doped $\mathrm{ZnO}$ with copper and maintain the nanorod like morphology. The $\mathrm{ZnO}$ nanorods are doped with different copper concentrations such as 5, 10, 15 and $20 \mathrm{mg}$. The pristine $\mathrm{ZnO}$ and copper doped $\mathrm{ZnO}$ nanostructures were used to degrade the methylene blue and methyl orange which are known as the most hazardous to the environment. The photo degradation efficiency for both $\mathrm{MO}$ and $\mathrm{MB}$ are compared, and photocatalytic mechanism has been proposed. We successively reduced the band gap of $\mathrm{ZnO}$ from 3.46 (pristine $\mathrm{ZnO}$ ) to $3.10 \mathrm{eV}$ with increase in copper content up to $20 \mathrm{mg}$. . It shows a significant effect of copper doping on band gap reduction leading to the increase in photocatalytic efficiency.

\section{Materials and Experimental Section}


Copper acetate $\left(\mathrm{Cu}(\mathrm{OAc})_{2}\right.$, zinc acetate-dihydrate $\left(\mathrm{ZnC}_{4} \mathrm{H}_{6} \mathrm{O}_{4}\right)$, ammonia solution, and ethanol $\left(\mathrm{C}_{2} \mathrm{H}_{5} \mathrm{OH}\right.$, were of analytical grade and received from Sigma-Aldrich), Karachi Pakistan. The deionized water was used for the preparation of solutions throughout the study.

We used low temperature aqueous method to get $\mathrm{ZnO}$ nanorods and their doped samples [40-41]. The zinc acetate dihydrate $\left(\mathrm{ZnC}_{4} \mathrm{H}_{6} \mathrm{O}_{4}\right)$ and ammonia $\left(\mathrm{NH}_{3}\right)$ solutions were mixed in the deionized water and copper acetate $\left(\mathbf{C u}(\mathbf{O A c})_{2}\right.$ was used as dopant source. The dopant concentration was varied such as (5 mg, $10 \mathrm{mg}, 15 \mathrm{mg}, 20 \mathrm{mg}$ and named as sample 1, 2, 3 and 4 respectively), then subsequently mixed with the precursor solution and uniform mixture was obtained by mechanical stirring for $30 \mathrm{~min}$. The zinc precursor $2.22 \mathrm{~g}$ of $\mathrm{ZnC}_{4} \mathrm{H}_{6} \mathrm{O}_{4}$ and $5 \mathrm{~mL}$ of $25 \%$ of ammonia solution was used for the preparation of pristine $\mathrm{ZnO}$ and copper doped samples. The growth solution was covered with the aluminum foil and kept in oven at $95^{\circ} \mathrm{C}$ for 6 hours. The nanostructured materials were obtained after the growth duration by filtration and dried at room temperature.

The crystalline features of as prepared samples investigated by the powder X-ray diffraction using (Make Panalytical X'Pert Pro $\mathrm{Cu} \mathrm{K \alpha}$ ), and Morphology of as prepared nanostructures was studied using scanning electron microscopy at the accelerating voltage of $3 \mathrm{kV}$. The photo catalytic and optical band gap studies were carried out by using UV-Vis spectrophotometer.

The photocatalytic study of synthesized pristine and copper doped $\mathrm{ZnO}$ nanorods for the degradation of $\mathrm{MO}$ and $\mathrm{MB}$ was carried out at the different intervals of time and UV light treatment. We have measured the degradation rate of both dyes in aqueous solution using fixed amount of $5 \mathrm{mg}$ photo catalysts. The concentration of MB and MO solution was taken $0.03 \mathrm{mM}$ The $\mathrm{pH}$ for the $\mathrm{MB}$ and $\mathrm{MO}$ was found 6.79 and 3.65 respectively. The photo catalytic activity was measured at different intervals of time and all other experimental conditions for the samples were same. Typically, in the measurement of photocatalytic activity, we used three $360 \mathrm{~nm}$ UV lamps of $10 \mathrm{~W}$ each. And fixed amount of photo catalyst and MO/MB were homogenized in 250 $\mathrm{mL}$ beaker using ultrasonic bath for 10 mints. Then solution was stirred via magnetic stirring for 30 mints in dark in order to ensure the adsorption-desorption equilibrium state for MO/MB on the surface of photo catalyst. Then UV light was applied to the solutions for different time intervals. During the irradiation of UV light, the suspension was collected and analyzed via UV-visible spectrophotometer (PE Lamda 35) with respect to maximum absorption of $\mathrm{MO} / \mathrm{MB}$ and to correlate the concentration of the $\mathrm{MO} / \mathrm{MB}$ in the solution

The calculation for the degradation efficiency was done via following equation: 
Degradation efficiency $\%=\frac{C o-C t}{C o} \times 100$

Here $C o$ is the initial MO/MB concentration $(\mathrm{mg} / \mathrm{L}), C t$ shows the $\mathrm{MO} / \mathrm{MB}$ concentration $(\mathrm{mg} / \mathrm{L})$ after at different intervals of irradiation times $(\mathrm{t})$. For confirming the pseudo order kinetics for the $\mathrm{MO}$ and MB using UV light as irradiant source and following equation was used ln_C0/Ct_=Kapp $\times t$

Herein, Kapp represents apparent rate constant, $C 0$ represents the initial MO concentration $(\mathrm{mg} / \mathrm{L})$ at irradiation time $0 \mathrm{~min}$, and $C t$ shows the $\mathrm{MO} / \mathrm{MB}$ concentration for the time $t 248(\mathrm{mg} / \mathrm{L})$. The UV-Visible absorbance spectra were recorded using $5 \mathrm{mg}$ of photo catalyst for the estimation of optical bandgap.

\section{Results and Discussionss}

The powder XRD was used to investigate the crystallography of as prepared nanostructured $\mathrm{ZnO}$ and copper doped $\mathrm{ZnO}$ as shown in Figure 1. The $\mathrm{ZnO}$ exhibits the wurtzite (hexagonal) phase and with the addition of copper impurity in the precursor of $\mathrm{ZnO}$ that did not bring any substantial changes in the intensity of diffraction patterns. The diffraction patterns related to pristine $\mathrm{ZnO}$ include $31.737^{\circ}(010), 34.420^{\circ}(002), 36.225^{\circ}(011), 47.515^{\circ}(012), 56.536^{\circ}(110), 62.836^{\circ}(013)$, $66.304^{\circ}(020), 67.893^{\circ}(112), 69.015^{\circ}(021)$, and $72.561^{\circ}(004), 76.891^{\circ}(022), 81.364^{\circ}(014)$, and 89.544 (023) and they are in good agreement with the standard JCPDS card no. 96-900-4182. Besides this, XRD was used record the changes in the crystallinity of copper doped ZnO samples and the patterns are indexed to the crystal planes at slight distortion of angle such as $31.777^{\circ}$, $34.433^{\circ}, 36.264^{\circ}, 47.554^{\circ}, 56.612^{\circ}, 62.879^{\circ}, 66.396^{\circ}, 67.97^{\circ}, 69.108^{\circ}, 72.594^{\circ}, 76.985^{\circ}, 81.417^{\circ}$ and $89.646^{\circ}$ seems which indicates that doping has changed the lattice location and which can be assigned to the substitutional doping of copper into $\mathrm{ZnO}$ crystal. All the diffraction patterns are in good agreement with the standard JCPDS card no96-230-0113. The XRD analysis indicates that copper is successfully doped into $\mathrm{ZnO}$ and no other impurity such as metallic copper or $\mathrm{Cu}_{2} \mathrm{O}$ or $\mathrm{CuO}$ was identified. 


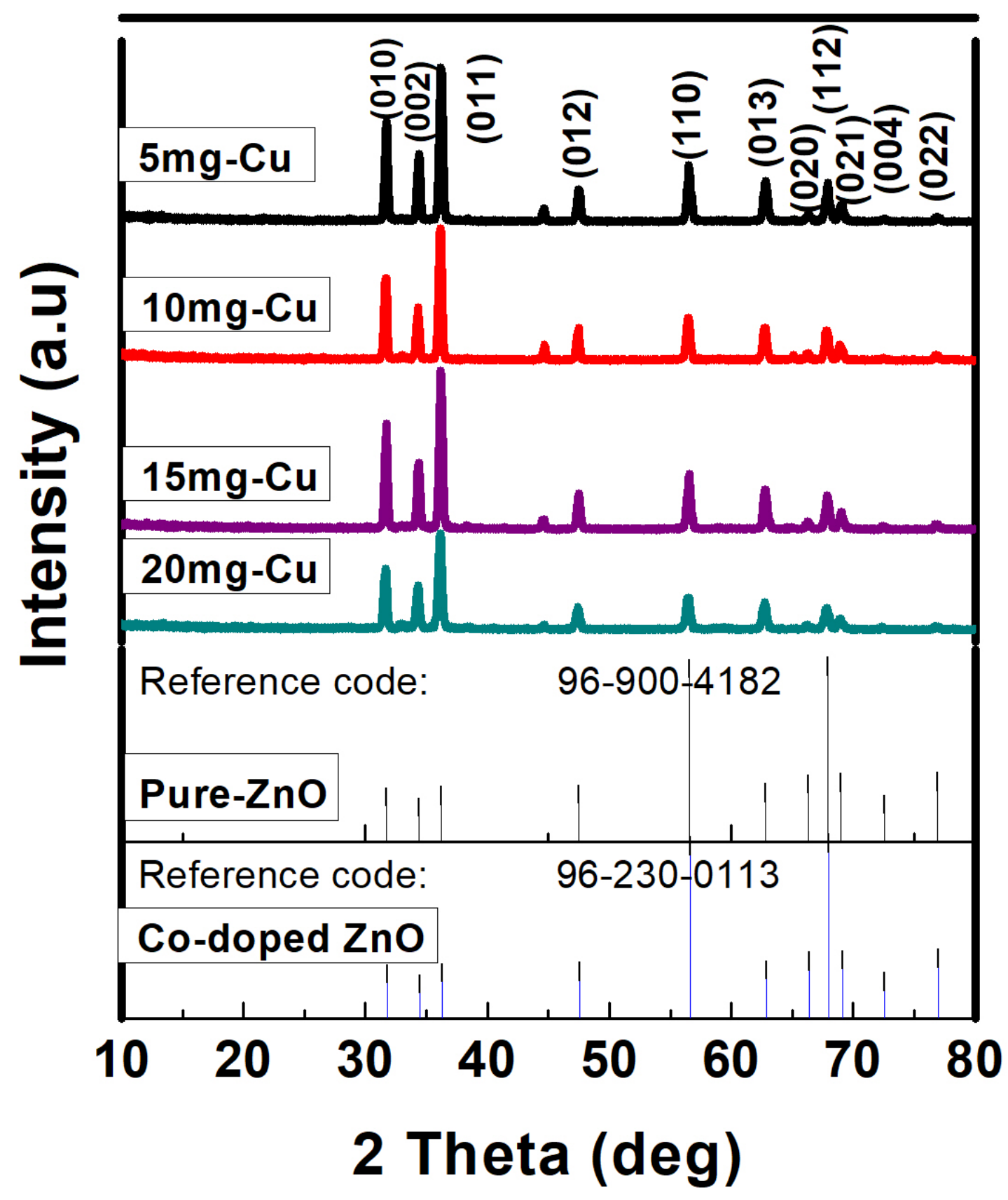


Figure1: The $\mathrm{XRD}$ spectra of undoped $\mathrm{ZnO}$ nanorods and copper doped $\mathrm{ZnO}$ nanorods with 5, 10,15 and $20 \mathrm{mg}$ copper dopant concentration

The shape features of as prepared pristine $\mathrm{ZnO}$ and copper doped $\mathrm{ZnO}$ are investigated by low resolution scanning electron microscopy as depicted in Figure 2. Figure 2a shows the SEM images of $5 \mathrm{mg}$ and $10 \mathrm{mg}$ copper doped $\mathrm{ZnO}$ and Figure $2 \mathrm{~b}$ for $15 \mathrm{mg}$ and $20 \mathrm{mg}$ copper doping in $\mathrm{ZnO}$ and Figure $\mathrm{S} 1$ shows the morphology of pristine $\mathrm{ZnO}$. The length of $\mathrm{ZnO}$ nanorods is few microns and diameter is in the range of 200-300 nm. The interesting point in SEM analysis is that before and after the copper doping there is no alternation in the morphology of $\mathrm{ZnO}$ and it remains well controlled in length and diameter. The EDS elemental mapping confirmed the uniform distribution of copper into $\mathrm{ZnO}$ nanorods and main elements are $\mathrm{Cu}, \mathrm{Zn}$ and $\mathrm{O}$ as shown in Figure $\mathrm{S} 2$. The impurity of $\mathrm{Cr}$ and $\mathrm{Ag}$ is emerged from the substrate. 

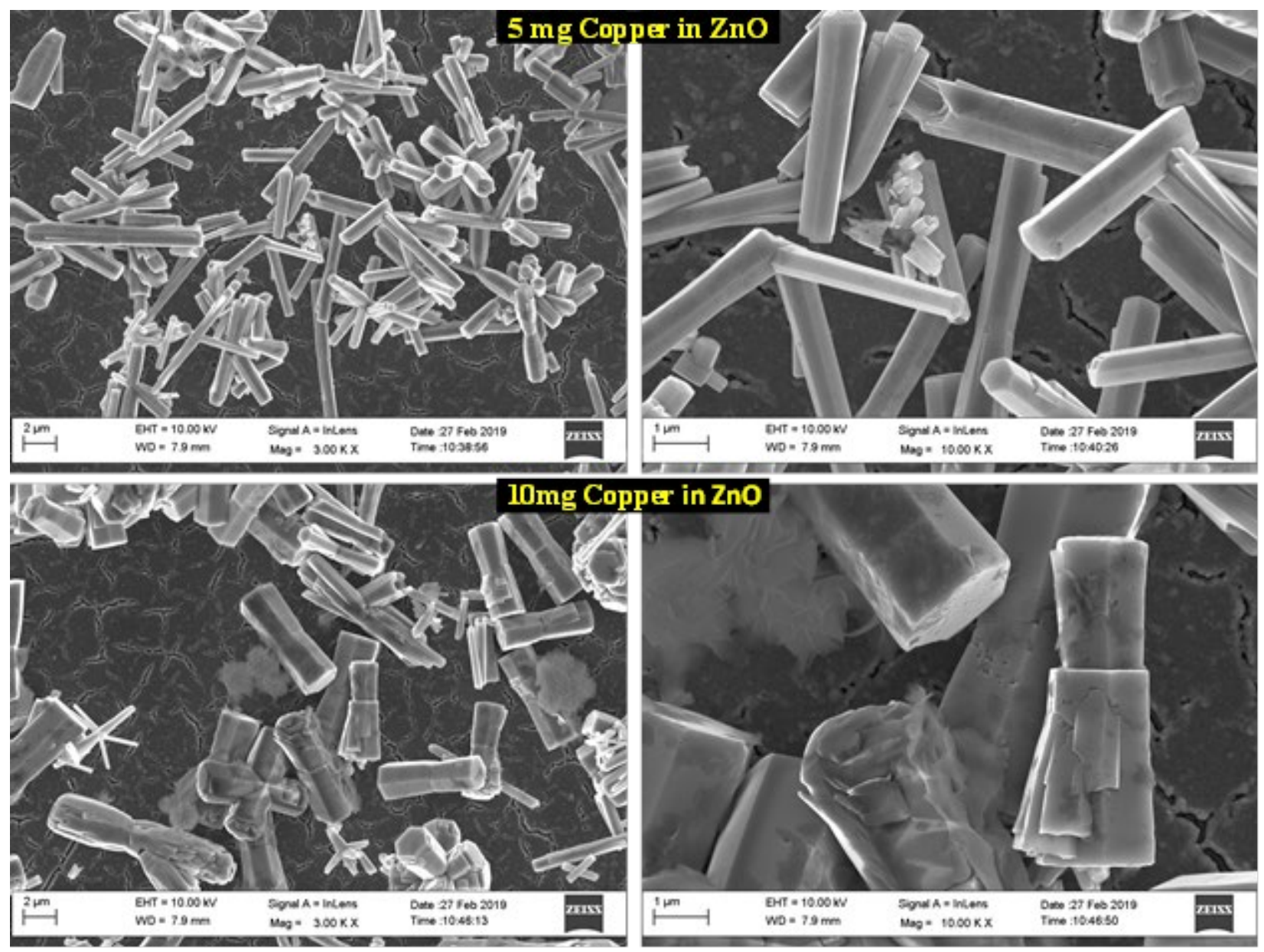

Figure 2a 

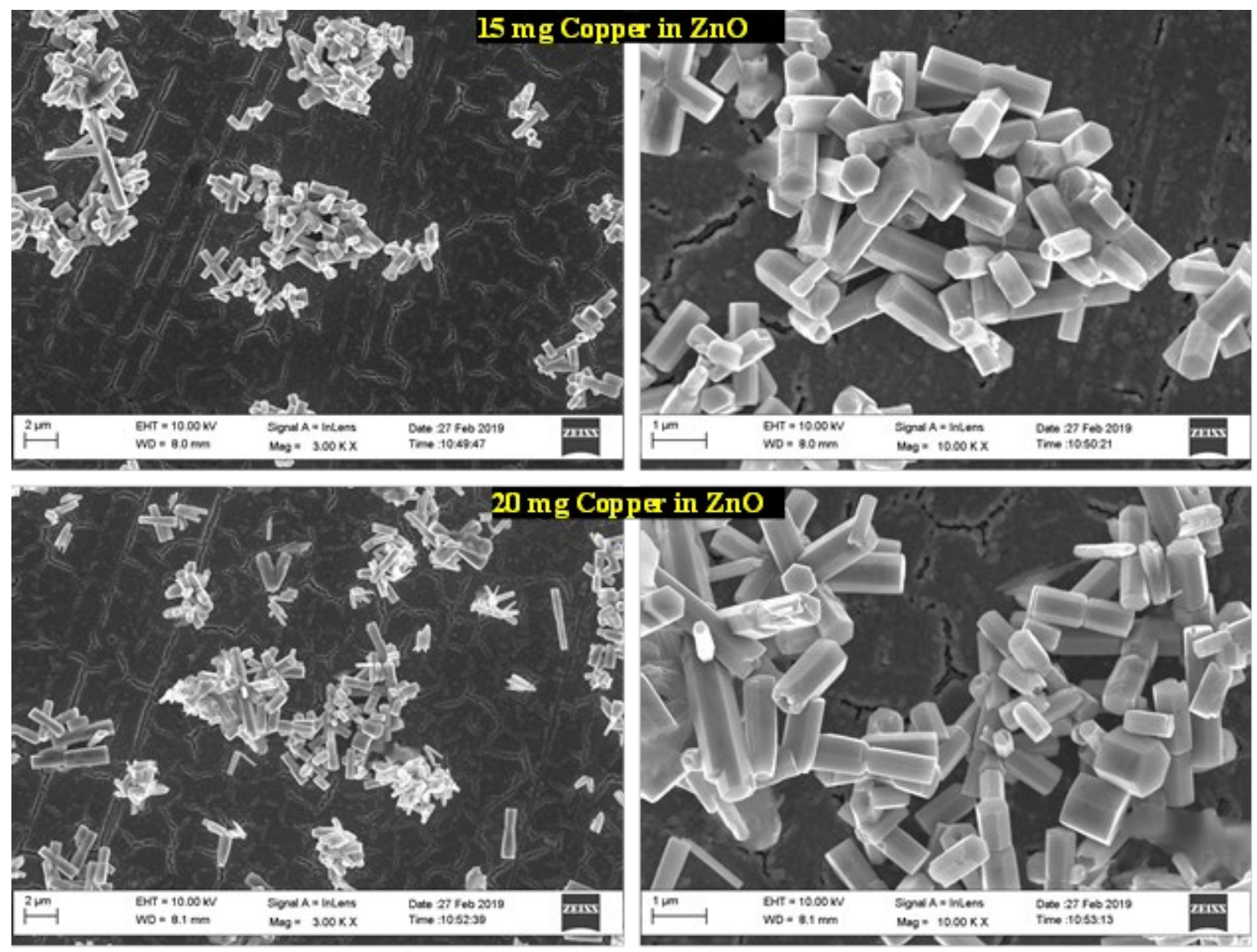

Figure 2b 
Figure 2: SEM images for $\mathrm{ZnO}$ nanorods doped with various concentrations of copper (a) $\mathrm{ZnO}$ nanorods doped with $5 \mathrm{mg}$ and $10 \mathrm{mg}$ of copper (b) SEM images of $\mathrm{ZnO}$ nanorods doped with $15 \mathrm{mg}$ and $20 \mathrm{mg}$ of copper

The photocatalytic activity of as prepared samples was monitored by the treatment of MB and MO dyes solution with UV light and the relative decrease in the UV-visible light absorption at different intervals of time as shown in Figure 3 for degradation of MO with Copper doping (a-d) and 4 for degradation of MB with copper content (a-d). In each dye solution a fixed amount of photo catalyst was added. The photo degradation efficiency was found increasing with increase in the concentration of copper dopant into the $\mathrm{ZnO}$ nanorods. 

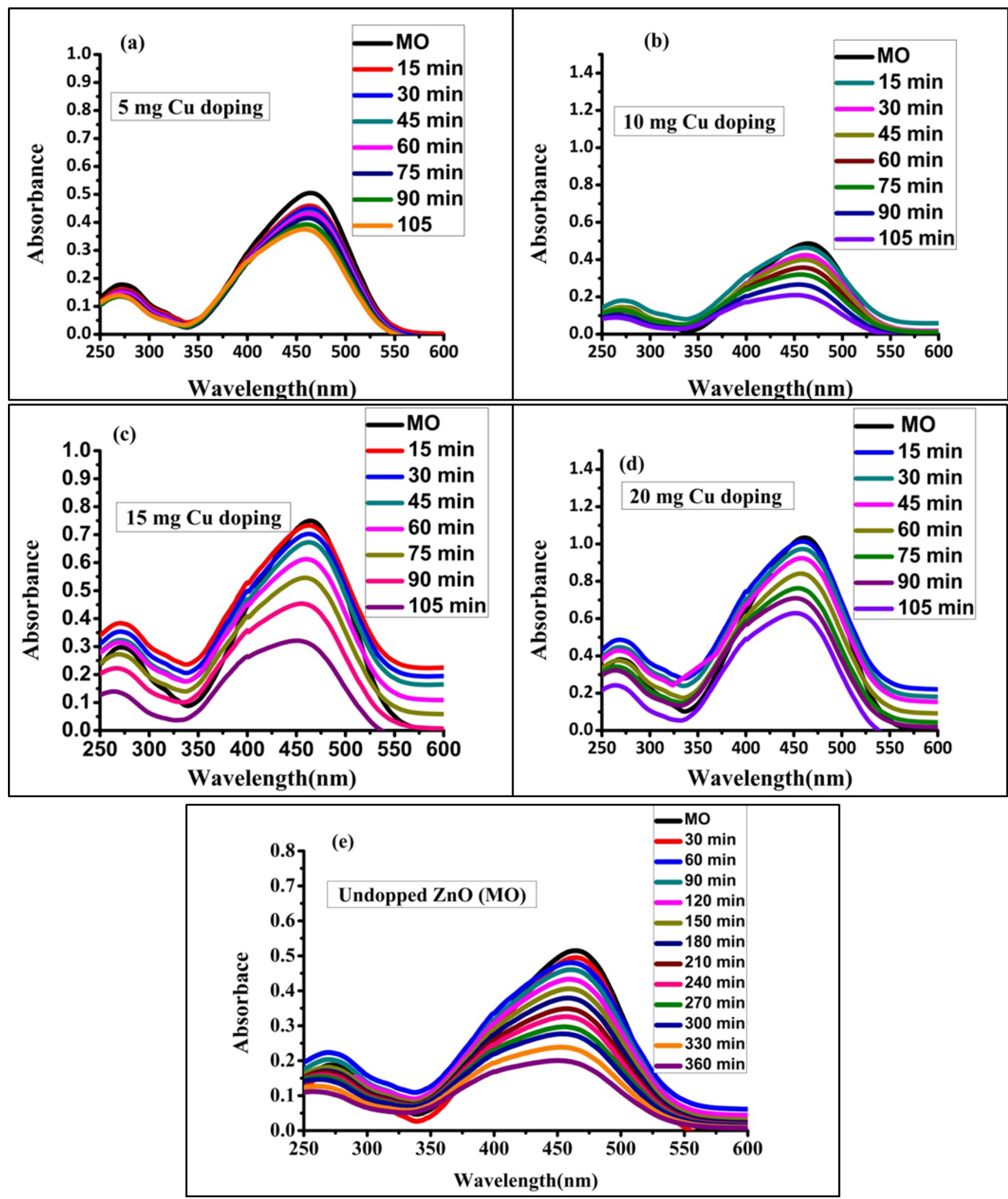
Figure 3: UV-Vis absorption spectra of various copper doped $\mathrm{ZnO}$ nanorods for degradation of $\mathrm{MO}$ at different time irradiations of 15, 30, 45, 60, 75, 90 and 105 minutes (e) UV-Visible absorption spectra of pure $\mathrm{ZnO}$ at different intervals of time. 

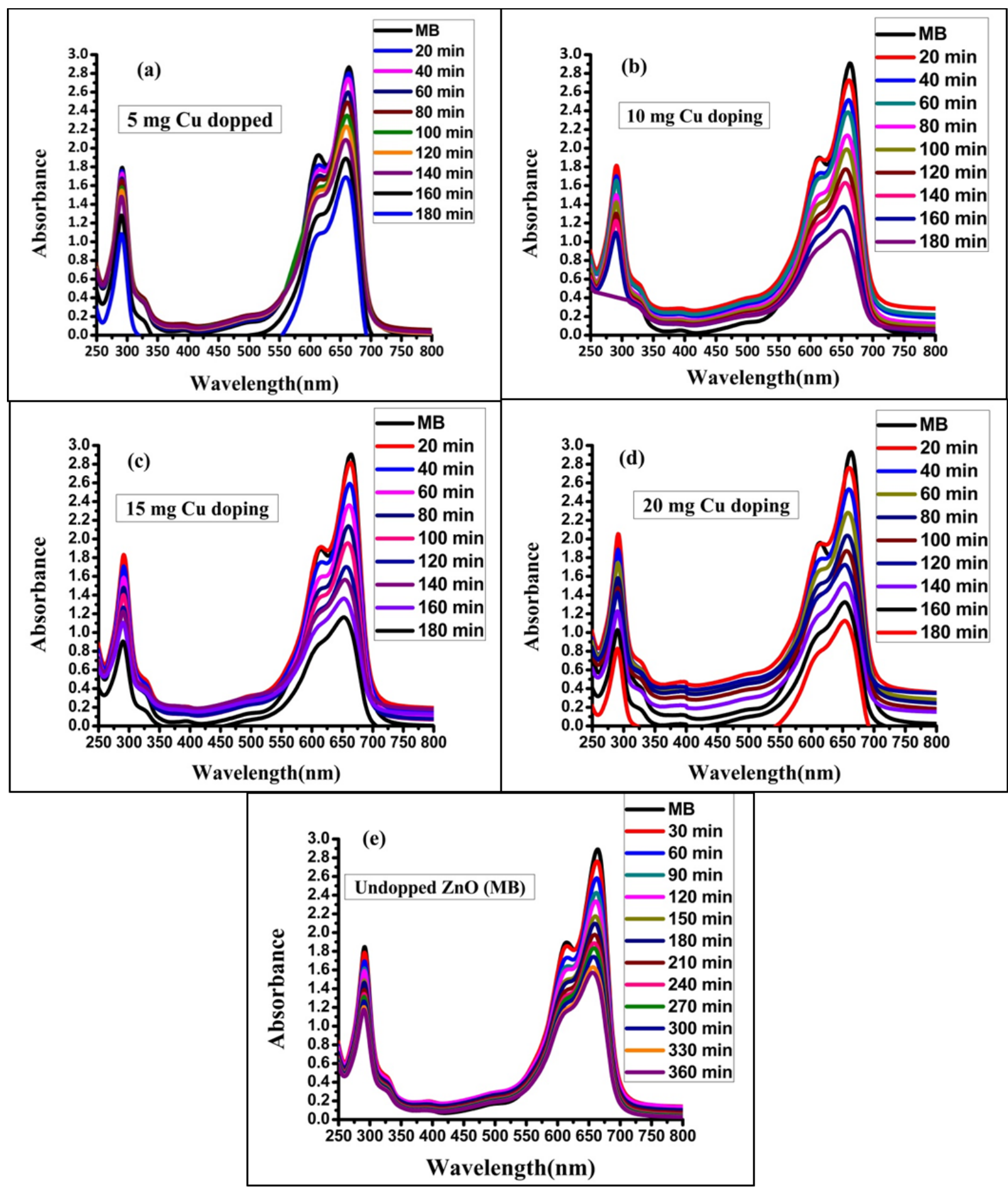

Figure 4: Figure 4: UV-Vis absorption spectra of various copper doped $\mathrm{ZnO}$ nanorods for degradation of $\mathrm{MB}$ at different time irradiations of 20 to 180 minutes at equal intervals of $20 \mathrm{~min}$ as compared to (e) pure $\mathrm{ZnO}$ for time irradiations of 30 to $360 \mathrm{~min}$ at equal intervals of $30 \mathrm{~min}$ respectively. 
At first photo degradation was performed on pristine $\mathrm{ZnO}$ in Methyl Orange (MO) for 360 minutes and it was found that the undoped $\mathrm{ZnO}$ progressively degraded up to maximum of $60 \%$ efficiency. (Figure 5b)

To investigate the photo catalytic effect of various copper doped $\mathrm{ZnO}$ nanostructures in the degradation of MO and it has been shown that copper doping has significantly changed the photo catalytic activity of $\mathrm{ZnO}$ when compared to the pristine $\mathrm{ZnO}$ as shown in Figure 5 (a). It has been seen that the photo degradation efficiency of $\mathrm{ZnO}$ was increased with the addition of increasing amount of copper. The maximum degradation efficiency of (57.5\%) was achieved with $10 \mathrm{mg}$ and $15 \mathrm{mg}$ of copper doping into $\mathrm{ZnO}$. Figure 5 Figure 5(c) indicates the pseudo first order reaction and the Figure 5 (d) shows the behavior of various photocatalysts against the time.

Figure 5(e) shows the photocatalytic spectra for the MO at different intervals of time for the pristine $\mathrm{ZnO}$ which reveals a long time for the partial degradation of $\mathrm{ZnO}$

It can been clearly observed that doping of copper has considerable time on degradation speed as it took about 360 minutes for undoped $\mathrm{ZnO}$ to degrade in MO (Fig: 5b) as compared to copper doped $\mathrm{ZnO}$ that took about 105 minutes to degrade enhancing the considerable effect of copper doping. 

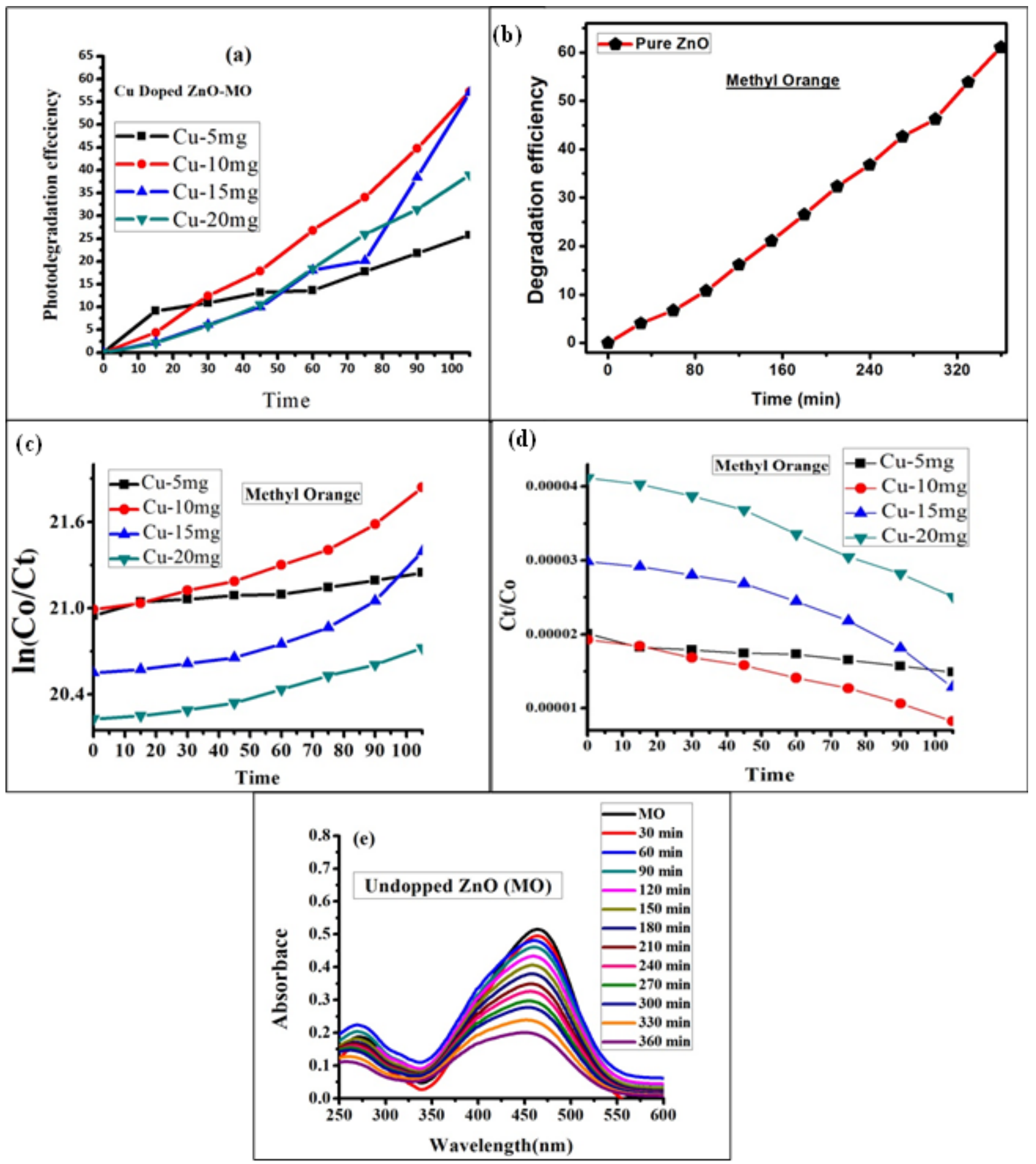

Figure 5: (a) Photo degradation efficiency of copper doped $\mathrm{ZnO}$ nanorods towards $\mathrm{MO}$ (b) Photo degradation of pristine $\mathrm{ZnO}$ in Methyl Orange (c) Plot of $\ln (\mathrm{Co} / \mathrm{Ct}$ versus time for illustrating the kinetics of photo degradation of $\mathrm{MO}$ with copper doped $\mathrm{ZnO}$ (d) Plot ct/Co versus 
time (e) UV-Visible absorption spectra of pure $\mathrm{ZnO}$ in the presence of $\mathrm{MO}$ at different intervals of time.

Initially pristine $\mathrm{ZnO}$ was degraded in Methylene Blue for about 360 minutes. It was found that $\mathrm{ZnO}$ degraded progressively up to $46 \%$ efficiency as shown in Figure $6 \mathrm{~b}$

Further, the dual photocatalytic activity of the prepared copper doped and pristine $\mathrm{ZnO}$ samples was investigated for the $\mathrm{MB}$ and considerable degradation efficiency was noticed for the copper doped samples as shown in Figure 6. There was a linear relation between the degradation rate with increasing increment of copper dopant into $\mathrm{ZnO}$ nanostructures and the degradation efficiency was monitored for the time period of 180 mints. The $20 \mathrm{mg}$ copper doped $\mathrm{ZnO}$ nanorods were found to be efficient photocatalyst with a degradation efficiency of (60\%) as shown in Figure 6 (a). Figure 6(c) shows the curve fitting which indicates the pseudo second order kinetics, however Figure 6(d) shows the pseudo first order fitting. The obtained value of slopes from the Figure 6(c, d) corresponds to the rate constants. The photo degradation mechanism for the methyl orange and methylene blue based on copper doped $\mathrm{ZnO}$ nanorods can be explained on the basis of optical band gap as smaller the band gap few chances for the recombination rate of electron and hole pairs as it gives a short time for the interaction among them. Greater the optical band gap, higher will be time for the interaction of electron and hole pairs that results into the fast charge recombination rate and consequently a poor photo degradation efficiency is found. Figure 6 (e) shows the degradation trend of $\mathrm{MB}$ versus degradation time for the pristine $\mathrm{ZnO}$. The pristine $\mathrm{ZnO}$ showed the slow kinetics of degradation and a poor degradation activity for the long time around 360 mints. However, the maximum degradation with copper doping was observed in 180 minutes i-e faster than the pristine $\mathrm{ZnO}$. After the comparison of photo degradation efficiency of both dyes, it can be seen that for the copper doped $\mathrm{ZnO}$ samples, there is increasing trend of degradation with increasing content of copper; however, for the MO the degradation is limited by $15 \mathrm{mg}$ doped $\mathrm{ZnO}$ samples. However, the $20 \mathrm{mg}$ copper doped sample of $\mathrm{ZnO}$ has demonstrated slow the degradation rate for $\mathrm{MO}$ which can be assigned to greater charge recombination rate of the sample when compared to other copper doped $\mathrm{ZnO}$ samples. Based on the degradation efficiency, $\mathrm{MO}$ has 57.5 $\%$ at time of 105 mints which is smaller than the MB that has $60 \%$ degradation efficiency. 


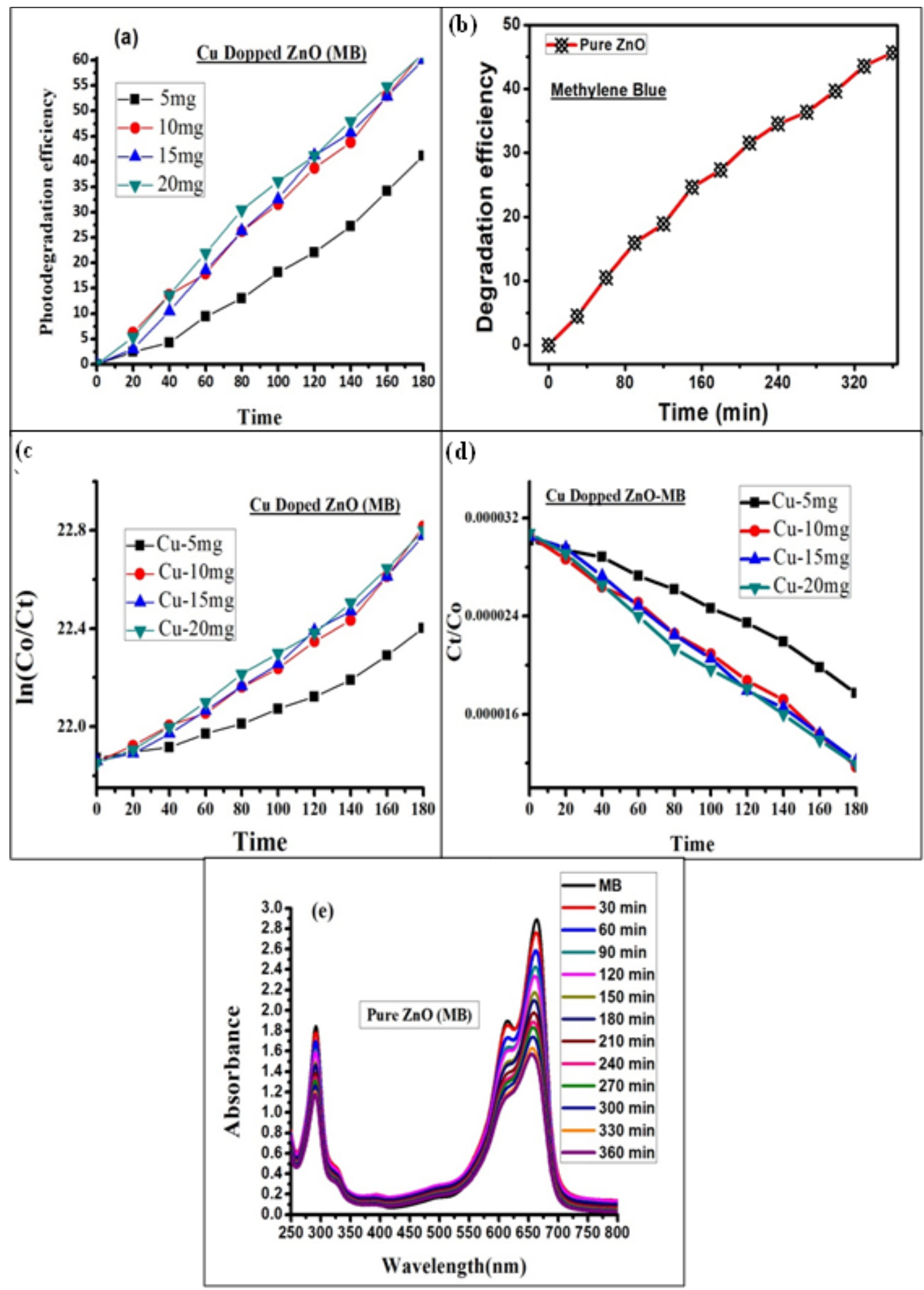

Figure 6: (a) photo degradation efficiency of copper doped $\mathrm{ZnO}$ nanorods towards $\mathrm{MB}$ (b) Photo degradation of pristine $\mathrm{ZnO}$ in Methylene blue (c)ln $\mathrm{Co} / \mathrm{Ct}$ versus time (d) Plot of $(\mathrm{C} / \mathrm{Co}$ ) versus 
time (e) UV-Visible absorption spectra of pure $\mathrm{ZnO}$ in the presence of $\mathrm{MB}$ degradation at different intervals of time.

The UV-visible spectra for the bandgap are shown in Figure 7. It is decreased during the doping of copper into $\mathrm{ZnO}$ compared to the pristine $\mathrm{ZnO}$. It is shown that low content of coper has brought reduction in band gap of \pm 0.71 at $250-600 \mathrm{~nm}$ and overall doped $\mathrm{ZnO}$ nanorods exhibit low optical bandgap when compared to the pure $\mathrm{ZnO}$. Also it is worth to mention herein that the reduced band gap has significant effect on photo degradation efficiency.. The measured optical band gas $\mathrm{ZnO}$ nanostructures is given in Table 1.

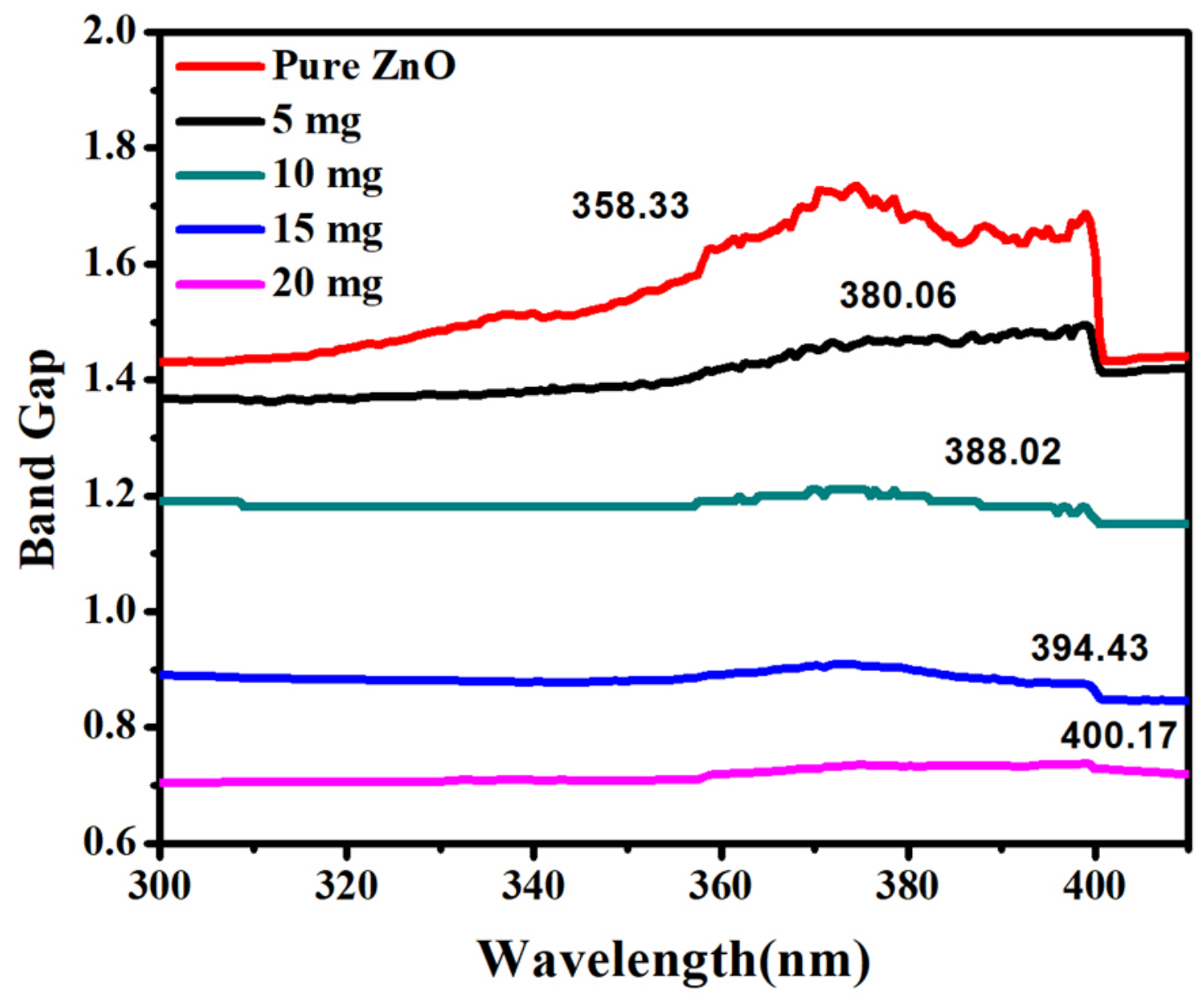

Figure 7: UV-Visible absorption spectra of un doped $\mathrm{ZnO}$ nanorods and copper doped $\mathrm{ZnO}$ 
Table 1: Measured optical bandgap from UV-visible spectra

\begin{tabular}{|c|c|c|}
\hline Name of Samples & Cut of wavelength & Band gap (eV) \\
\hline Pure $\mathrm{ZnO}$ & 358.33 & 3.46 \\
\hline $5 \mathrm{mg}$ & 380.06 & 3.26 \\
\hline $10 \mathrm{mg}$ & 388.02 & 3.19 \\
\hline $15 \mathrm{mg}$ & 394.43 & 3.14 \\
\hline $20 \mathrm{mg}$ & 400.17 & 3.10 \\
\hline
\end{tabular}

\section{Conclusionss}

In summary, $\mathrm{ZnO}$ nanorods are successfully doped with different content of copper and were used as efficient photocatalyst for the photo degradation of MO and MB. The XRD study reveals minor crystallographic changes in the $\mathrm{ZnO}$ crystal lattice after copper doping and they exhibit the hexagonal phase. Further SEM study confirms no change in the morphology of $\mathrm{ZnO}$ with addition of different concentrations of copper. The optical band gap was decreased with increase in the dopant concentration and it prevents the interaction of electron and hole pairs thus charge recombination rate is minimized. Upto $10.4 \%$ of decrease in band gap was achieved with copper doping of up to $20 \mathrm{mg}$ endorsing the considerable effect of copper doping on optical bandgap. The photo degradation efficiency for the MO was found to be $57.5 \%$ and $60 \%$ for the MB. The proposed catalysts are promising for the wastewater treatment and other environmental applications.

\section{References}


[1] U.G. Akpan, B.H. Hameed, Parameters affecting the photocatalytic degradation of dyes using $\mathrm{TiO}_{2}$-based photocatalysts: A review, Journal of Hazardous Materials 170 (2009) 520-529

https://doi.org/10.1016/j.jhazmat.2009.05.039

[2] B. Malini, G. Allen Gnana Raj, C,N and S-doped $\mathrm{TiO}_{2}$-characterization and photo catalytic performance for rose bengal dye degradation under day light, Journal of Environmental Chemical Engineering 6 (2018) 5763-5770

https://doi.org/10.1016/j.jece.2018.09.002

[3] S. Martínez-Lopez et al. ,Pulsed light for a cleaner dyeing industry: Azo dye degradation by an advanced oxidation process driven by pulsed light, Journal of Cleaner Production 217 (2019) 757-766

https://doi.org/10.1016/j.jclepro.2019.01.230

[4] S.M. Saleh, $\mathrm{ZnO}$ nanospheres based simple hydrothermal route for photocatalytic degradation of azo dye Spectrochimica ActaPart A, Molecular and Biomolecular Spectroscopy 211 (2019) 141-147

https://doi.org/10.1016/j.saa.2018.11.065

[5] D. Smazna, et al. Mutual interplay of $\mathrm{ZnO}$ micro- and nanowires and methylene blue during cyclic photocatalysis process, Journal of Environmental Chemical Engineering 7 (2019) 103016

https://doi.org/10.1016/j.jece.2019.103016

[6] Wei Li, Guojing Wang, Chienhua Chen, Jiecui Liao and Zhengcao Li, Enhanced Visible Light Photo catalytic Activity of $\mathrm{ZnO}$ Nanowires Doped with $\mathrm{Mn} 2+$ and Co2+ Ions, Nanomaterials, 2017, 7(1), 20

https://doi.org/10.3390/nano7010020 
[7] Indar Kustiningsih, Slamet, Widodo Wahyu Purwanto, Synthesis of Titania Nanotubes and Titania Nanowires by Combination Sonication-hydrothermal Treatment and their Photocatalytic Activity for Hydrogen Production, International Journal of Technology (2014) 2: 133-141

http://dx.doi.org/10.14716/ijtech.v5i2.400

[8] Wen-Dong Wei, Xiang-Yu Liu, Shi-Cong Cui, Jin-Gang Liu, Loading of Co3O4 onto Pt-modified nitrogen-doped $\mathrm{TiO} 2$ nanocomposites promotes photocatalytic hydrogen production, RSC Adv.,(2017), 7, 25650-25656

https://doi.org/10.1039/c7ra03216a

[9] Bei Cheng, Yao Le, Jiaguo Yu., Preparation and enhanced photocatalytic activity of $\mathrm{Ag} @ \mathrm{TiO}_{2}$ core-shell nanocomposite nanowires, Journal of Hazardous Materials 177 (2010) 971-977

https://doi.org/10.1016/j.jhazmat.2010.01.013

[10] M.A. Hernández-Carrillo et al. Eu-modified $\mathrm{ZnO}$ nanoparticles for applications in photocatalysis, Catalysis Today (2019) (In Press)

https://doi.org/10.1016/j.cattod.2018.04.060

[11] Bharat Baruah, Latanya Downer, David Agyeman, Fabric-based composite materials containing ZnO-NRs and ZnO-NRs-AuNPs and their application in photocatalysis, Materials Chemistry and Physics 231 (2019) 252-259

https://doi.org/10.1016/j.matchemphys.2019.04.006

[12] Qiong Zhou, John Z. Wen, Pei Zhao and William A. Anderson, Synthesis of Vertically-Aligned Zinc Oxide Nanowires and Their Application as a Photocatalyst, Nanomaterials (2017), 7, 9

https://doi.org/10.3390/nano7010009 
[13] Sonal Singhal, Japinder Kaur, Tsering Namgyal and Rimi Sharma, Cu-doped ZnO nanoparticles: Synthesis, structural and electrical properties, Physica B: Condensed Matter, 407 (2012) 1223-1226

https://doi.org/10.1016/j.physb.2012.01.103

[14] Rajneesh Mohana, Karthikeyan Krishnamoorthy and Sang-Jae Kim, Enhanced photocatalytic activity of $\mathrm{Cu}$-doped $\mathrm{ZnO}$ nanorods, Solid State Communications 152 (2012) 375-380

https://doi.org/10.1016/j.ssc.2011.12.008

[15] S.Sriram, K.C. Lalithambika, A.Thayumanavan, Experimental and theoretical investigations of photocatalytic activity of $\mathrm{Cu}$ doped $\mathrm{ZnO}$ nanoparticles, Optik 139 (2017) 299-308

http://dx.doi.org/10.1016/j.ijleo.2017.04.013

[16] M. C. Uribe López et al. Synthesis and Characterization of $\mathrm{ZnO}-\mathrm{ZrO} 2$ Nanocomposites for Photocatalytic Degradation and Mineralization of Phenol, Journal of Nanomaterials, Volume 2019

https://doi.org/10.1155/2019/1015876

[17] DongminAn, QiongWang, XiaoqiangTong, Xiaoxue Lian, Yunling Zou and Yan Li, $\mathrm{ZnO}$-enhanced In2O3-based sensors for n-butanol gas , Ceramics International 45 (2019) 6869-6874

https://doi.org/10.1016/j.ceramint.2018.12.182

[18] B.R. Lee, et al. Highly efficient flexible organic photovoltaics using quasi-amorphous $\mathrm{ZnO} / \mathrm{Ag} / \mathrm{ZnO}$ transparent electrodes for indoor applications, Journal of Power Sources 417 (2019) 61-69

https://doi.org/10.1016/j.jpowsour.2019.02.015 
[19] P. Meng, et al. Stable electrical properties of $\mathrm{ZnO}$ varistor ceramics with multiple additives against the AC accelerated aging process, Ceramics International 45 (2019) 11105-11108 https://doi.org/10.1016/j.ceramint.2019.01.260

[20] Y. Peng etal. Achieving high-resolution pressure mapping via flexible $\mathrm{GaN} / \mathrm{ZnO}$ nanowire LEDs array by piezo-phototronic effect, Nano Energy 58 (2019) 633-640 https://doi.org/10.1016/j.nanoen.2019.01.076

[21] S. Vijayakumar, B. Vaseeharan, Antibiofilm, anti-cancer and ecotoxicity properties of collagen based ZnO nanoparticles, Advanced Powder Technology 29 (2018) 23312345

https://doi.org/10.1016/j.apt.2018.06.013

[22] Adel A. Ismail, Detlef W. Bahnemann, Photochemical splitting of water for hydrogen production by photocatalysis: A review, Solar Energy Materials and Solar Cells 128 (2014) 85-101

https://doi.org/10.1016/j.solmat.2014.04.037

[23] G. Vijayaprasath, R. Murugan, T. Mahalingam, Y. Hayakawa, G. Ravi, Enhancement of ferromagnetic property in rare earth neodymium doped $\mathrm{ZnO}$ nanoparticles, Ceram. Int. 41 (2015) 10607-10615. https://doi.org/10.1016/j.ceramint.2015.04.160

[24] Sanjay Gopal Ullattil, Pradeepan Periyat, Binu Naufal, Manoj Ainikalkannath Lazar, Self-doped $\mathrm{ZnO}$ micro rods high temperature stable oxygen deficient platforms for solar photo catalysis, Ind.

Eng. Chem. Res. 55 (2016) 6413-6421.

https://doi.org/10.1021/acs.iecr.6b01030 
[25] Yongchun Lu, Yanhong Lin, Tengfeng Xie, Shoulei Shi, Haimei Fana and Dejun WangY.C. Enhancement of visiblelight-driven photoresponse of $\mathrm{Mn} / \mathrm{ZnO}$ system: photogenerated charge transfer properties and photocatalytic activity, Nanoscale 4 (2012)

https://doi.org/10.1039/C2NR31671D

[26] M.B. Suwarnkar, R.S. Dhabbe, A.N. Kadam, K.M. Garadkar, Enhanced photo catalytic activity of $\mathrm{Ag}$ doped $\mathrm{TiO} 2$ nanoparticles synthesized by a microwave assisted method, Ceram. Int. 40 (2014) 5489-5496.

https://doi.org/10.1016/j.ceramint.2013.10.137

[27] Bresser Dominic et al. Transition-Metal-Doped Zinc Oxide Nanoparticles as a New Lithium-Ion Anode Material, Chem Mater 2013 https://doi.org/10.1021/cm403443t

[28] Afshin Maleki, Mahdi Safari," Photocatalytic degradation of humic substances in aqueous solution using $\mathrm{Cu}$-doped $\mathrm{ZnO}$ nanoparticles under natural sunlight irradiation",Environmental Science and Pollution Research, 22, (21) 2015, 1687516880 .

https://doi 10.1007/s11356-015-4915-7

[29] A. Maleki , B. Shahmoradi, "Solar degradation of Direct Blue 71 using surface modified iron doped $\mathrm{ZnO}$ hybrid nanomaterials"

Water Science and Technology, 65(11) 2012, Pages 1923-1928.

https://doi: 10.2166/wst.2012.091

[30] Roya Ebrahimi et al. "Effects of doping zinc oxide nanoparticles with transition metals $(\mathrm{Ag}, \mathrm{Cu}, \mathrm{Mn}$ ) on photocatalytic degradation of Direct Blue 15 dye under UV and visible light irradiation" Journal of Environmental Health Science and Engineering,17(1), pp. 479-492.

https://doi.org/10.1007/s40201-019-00366-x 
[31] Khosro Hossienzadeh, Afshin Maleki," Sonocatalytic and photocatalytic efficiency of transition metal-doped $\mathrm{ZnO}$ nanoparticles in the removal of organic dyes from aquatic environments"Korean Journal of Chemical Engineering, 36(8), pp. 13601370 .

https://doi: $10.1007 / \mathrm{s} 11814-019-0299-6$

[32]

Behzad Shahmoradi, Mahin Negahdary, and Afshin Maleki, "Hydrothermal

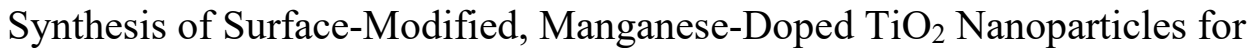
Photodegradation of Methylene Blue "

Environmental Engineering Science, 29 (11) 2012, Pages 1032-1037.

https://doi.org/10.1089/ees.2011.0519

[33] B. Shahmoradi, A. Maleki and K. Byrappa, "Removal of Disperse Orange 25 using in situ surface-modified iron-doped $\mathrm{TiO}_{2}$ nanoparticles"

Desalination and Water Treatment, 53, (13), 2015, Pages 3615-3622.

https://doi.org/10.1080/19443994.2013.873994

[34] A.N. Kadam, Taek Gon Kim, Dong Su Shin, K.M.Garadkar, Jinsub Park, Morphological evolution of $\mathrm{Cu}$ doped $\mathrm{ZnO}$ for enhancement of photocatalytic activity, Journal of Alloys and Compounds 710 (2017) 102-113 https://doi.org/10.1016/j.jallcom.2017.03.150

[35] Hye Seong Jung, Young Joon Hong, Yirui Li, Jeonghui Cho, Yong-Jin Kim and GyuChul Yi., Photocatalysis Using GaN Nanowires, ACS nano (2008) Vol. 2, No. 4, 637 642

https://doi.org/10.1021/nn700320y

[36] Chaiti Ray ${ }^{a}$ and Tarasankar Pal "Recent advances of metal-metal oxide nanocomposites and their tailored nanostructures in numerous catalytic applications" J. Mater. Chem. A, 2017,5, 9465-9487

Doi.org/10.1039/C7TA02116J 
[37] Anubha Jain, P.Sagar, R.M.Mehra, "Band gap widening and narrowing in moderately and heavily doped $\mathrm{n}-\mathrm{ZnO}$ films

"Solid-State Electronics

Volume 50, Issues 7-8, July-August 2006, Pages 1420-1424

https://doi.org/10.1016/j.sse.2006.07.001

[38] Abdus Saboor, Syed Mujtaba Shah, HazratHussain,” Band gap tuning and applications of $\mathrm{ZnO}$ nanorods in hybrid solar cell: Ag-doped verses Nd-doped $\mathrm{ZnO}$ nanorods", Materials Science in Semiconductor Processing

Volume 93, April 2019, Pages 215-225

https://doi.org/10.1016/j.mssp.2019.01.009

[39] A.ModwiaMohamed A.Ghanem "Lowering energy band gap and enhancing photocatalytic properties of $\mathrm{Cu} / \mathrm{ZnO}$ composite decorated by transition metals", Journal of Molecular Structure Volume 1173, 5 December 2018, Pages 1-6

https://doi.org/10.1016/j.molstruc.2018.06.082

[40] Jianhua Zhang et al. Study on the electrical properties of nano ZnO/PET-ITO heterojunction prepared by hydrothermal method, Journal of Electron Spectroscopy and Related Phenomena (2019)

https://doi.org/10.1016/j.elspec.2019.04.006

[41] Sayed M. Saleh, $\mathrm{ZnO}$ nanospheres based simple hydrothermal route for photocatalytic degradation of azo dye, Spectrochimica Acta Part A: Molecular and Bio molecular Spectroscopy 211 (2019) 141-147

https://doi.org/10.1016/j.saa.2018.11.065

\section{Supplementary Data}

Facile synthesis of copper doped $\mathrm{ZnO}$ nanorods for the efficient photo degradation of methylene blue and methyl orange 
Aqeel Ahmed Shah ${ }^{\mathrm{a}}$, Muhammad Ali Bhatti ${ }^{\mathrm{b}}$, Aneela Tahira ${ }^{\mathrm{e}}$, Ali Dad Chandio ${ }^{\mathrm{a}}$, Iftikhar A. Channa $^{\mathrm{a}}$, Ali Ghulam Sahito ${ }^{\mathrm{d}}$, Syed Ebrahim ${ }^{\mathrm{e}}$, Magnus Willander ${ }^{\mathrm{e}}$, Omer Nur ${ }^{\mathrm{e}}$, Zafar Hussain Ibupoto* c

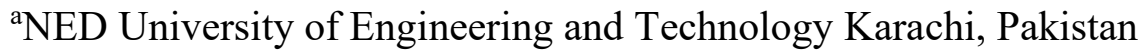

${ }^{b}$ Department of Environmental Sciences University of Sindh Jamshoro, 76080, Sindh Pakistan

${ }^{\mathrm{c}}$ Dr. M.A Kazi Institute of Chemistry University of Sindh Jamshoro, 76080, Sindh Pakistan

${ }^{\mathrm{d}}$ Centre for Pure and Applied Geology, University of Sindh Jamshoro, 76080, Sindh, Pakistan

e Department of Science and Technology, Campus Norrkoping, Linkoping University, SE-60174

Norrkoping, Sweden

*Corresponding author: Zafar Hussain Ibupoto

Email address: zaffar.ibhupoto@usindh.edu.pk

S1: SEM image of pristine $\mathrm{ZnO}$

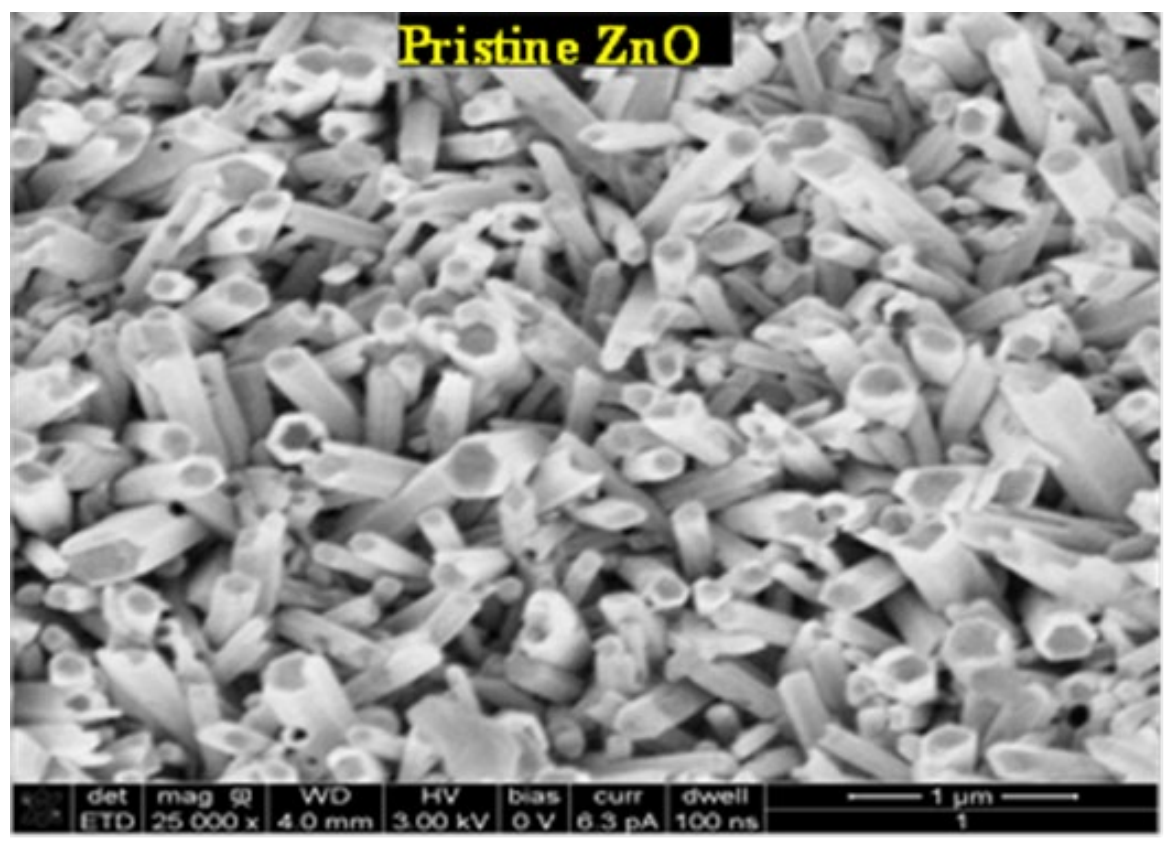


S2: Elemental mapping and EDS spectra of copper doped $\mathrm{ZnO}$ nanorods
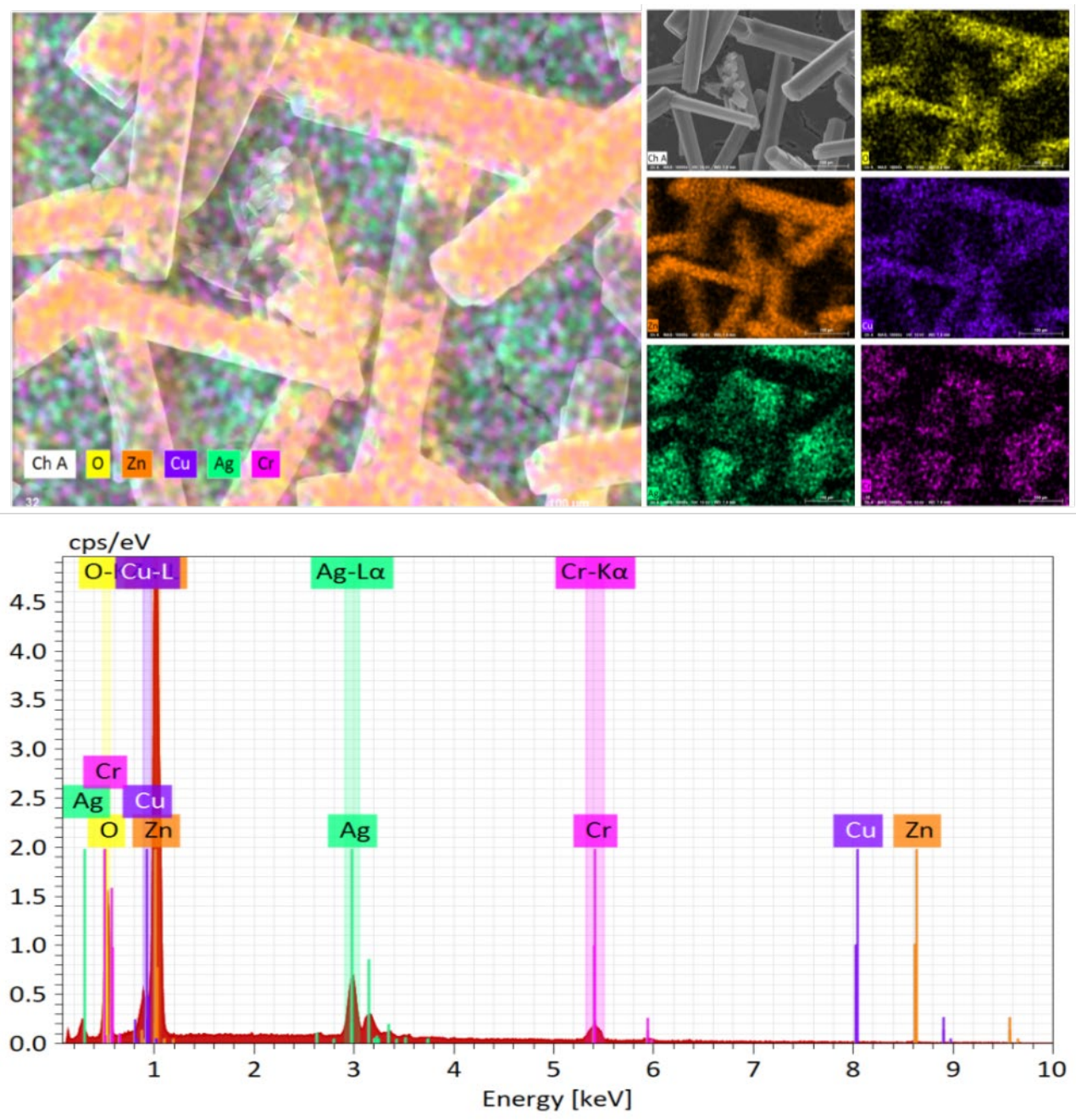